\title{
El Estado y la organización social en la producción y distribución del café en los Andes venezolanos
}

\author{
Rita Giacalone \\ Facultad de Ciencias JuRfidicas y Polfticas \\ UNIVERSIDAD DE LOS ANDES
}

Se analiza el proceso de penetración del Estado en la producción y comercialización del café en los Andes venezolanos entre 1958 y 1992, para mostrar que en ese proceso se formaron nuevos grupos en los que participaron sectores sociales tradicionales que así, no sólo pervivieron, sino que obtuvieron beneficios de su asociación con el Estado.

$\mathrm{E}$ n economías caracterizadas por la presencia de múltiples peque1 nos productores de un mismo rubro, el control del mercado ofrece las mejores oportunidades de alcanzar riqueza y poder. La capacidad de los intermediarios para fijar y manipular precios resulta crucial en este sentido, ${ }^{1}$ pero en áreas dominadas por una agricultura campesina hay otros elementos, aparte del estrictamente económico, que se asocia al poder de los intermediarios. En los Andes venezolanos esto se observa tanto en el pe-

1 Lópcz y Dorsainvil, "An analysis", 1990. riodo 1958-1973, cuando los intermediarios privados controlaban la comercialización del café, como en el periodo posterior a 1974, cuando el gobierno impuso su control monopólico a través de un ente estatal, el Fondo Nacional del Café (FONCAFE).

En este trabajo analizaremos el proceso de penetración del Estado en la producción y comercialización del café en los Andes venezolanos a lo largo de los años entre 1958 y 1992 . En el periodo posterior a 1958 los gobiernos del nuevo sistema democrático utilizaron este tipo de penetración para alterar los patrones tradicionales de 
poder económico y social en la región andina. Sin negar los cambios logrados, nuestro objetivo es demostrar que, a partir de 1974, en torno de las instituciones burocráticas de FONCAFE a nivel local se organizaron núcleos de poder, conformados por sectores sociales preexistentes junto con otros nuevos: especialmente nos interesa destacar que, en la conformación de esos nucleos, participaron en forma activa sectores tradicionales andinos, que lograron de esta forma asociarse al poder del Estado y utilizarlo en provecho propio.

El área geográfica en consideración abarca tres estados venezolanos (Tachira, Mérida y Trujillo) ubicados en el ángulo sudoccidental del país, cerca de la frontera con Colombia (véase mapa en apéndice), y caracterizados por su relieve montañoso. Condiciones favorables como la ausencia de extremos de frío o calor $y$ un patrón fijo de lluvia que oscila entre 1200 y $1800 \mathrm{~mm}$ entre abril y diciembre facilitaron la rápida expansión de la agricultura cafetalera en las laderas que se orientan hacia el lago de Maracaibo o hacia los Llanos desde la segunda mitad del siglo XIX. El aislamiento de esta región con respecto al área central venezolana, asolada por guerras civiles, la convirtió además en un oasis pacífico donde se refugió población que huía de los enfrentamientos entre caudillos, contribuyendo a aumentar la mano de obra disponible para las tareas agrícolas. ${ }^{2}$

2 Morales, "Origine", 1991; Roscherry, Coffee, 1983.
Para fines del siglo XIX el café era el producto dominante en la economía regional. Su producción se orientaba hacia el mercado internacional por medio de una red de casas comerciales europeas, especialmente alemanas e italianas, cuyas centrales se ubicaban en el puerto de Maracaibo y sus sucursales en las principales ciudades andinas. ${ }^{3}$ Después de alcanzar su tope máximo en términos de volumen de exportación en 1919, el café perdió su ubicación como principal producto de exportación y fue reemplazado cada vez más por el petróleo después de la década de $1920 .{ }^{4}$ Sin embargo, en el área objeto de nuestro análisis ni la depresión de los años 1930 ni la segunda guerra mundial ofrecieron una alternativa al cultivo del café para los pequeños productores campesinos. 5

En 1958 una coalición de partidos políticos reformistas, en unión con elementos militares y otros del sector económico dominante, impuso un gobierno de "conciliación de elites" con un proyecto orientado a modernizar Venezuela en forma rápida. En el caso de la región andina, el problema que se planteó fue cómo llevar a cabo esa modernización sin desplazar a los campesinos hacia las zonas urbanas, afectadas por un exceso de población marginal y por la carencia de servicios públicos adecuados. Los campesinos de los Andes debían recibir incentivos para seguir trabajando la tierra pero, a la vez, debían incorporarse a

\footnotetext{
3 Pouyllau, "Base territorialc", 1988.

4 Toulet, "Role", 1991.

5 Samudio, "Production", 1991.
} 
la Venezuela moderna que se aspiraba a constituir, tanto en su condición económica de productores-consumidores como en su condición política de ciudadanos-votantes. Quizá esta última consideración inspiró a Acción Democratica (AD), el partido que controló el gobierno venezolano durante la década de 1960, para intentar un programa que alterara las relaciones socioeconómicas preexistentes. Este partido tenía pocos seguidores en los Andes, dominados tradicionalmente por la Iglesia católica que consideraba comunistas a los "adecos" (miembros de AD), y en lo político, por el partido apoyado por la Iglesia, COPEI. Ún problema adicional para AD era el hecho de que su arma de movilización campesina, la reforma agraria, carecia de importancia en una región donde la mayoría de los campesinos eran dueños de su tierra, aunque fuera en pequeñas parcelas. ${ }^{6}$

\section{REIACIONES SOCIALES LOCALES} EN TORNO DE LA COMTRCIALIZACIÓN DEL CAFE EN LOS ANDFS VI:NEZOIANOS (1958-1973)

Para el año 1958 las relaciones sociales locales que rodeaban la comercialización del café en los Andes todavía seguían patrones establecidos durante el auge de final del siglo XIX, cuando casas comerciales europeas controlaban el sistema. Los productores cafetaleros mayores, con capacidad económica para asegurar el transpor1971.

6 Lord, Peasantry, 1967; Powcll, Political

EL ESTADO Y LA ORGANIZACIÓN SOCIAL te del producto a los puertos o a la industria nacional torrefactora desde la aislada y montañosa región andina, actuaban como intermediarios, tal como las casas comerciales habian actuado hasta la depresión o, en algunos casos, hasta el comienzo de la segunda guerra mundial. Estos productores asumían también el financiamiento de la producción por medio de pagos anticipados por la entrega de la cosecha, lo que hacía posible la subsistencia de la familia campesina hasta el momento de la recolección. Además, usualmente las relaciones entre pequeños productores e intermediarios reflejaban pirámides de poder en las cuales productores medianos compraban y financiaban la producción cafetalera de los más pequeños, pero a su vez eran proveedores de café y deudores de productores más grandes o ubicados más centralmente dentro del circuito de comercialización. No sólo los productores actuaban como intermediarios: "bodegueros" (pequeños o medianos comerciantes) ubicados en los pueblos y ciudadades de la región, así como camioneros que disponían de la infraestructura necesaria para el transporte del producto, cumplian las mismas funciones para los productores campesinos.

Una serie de informes de diversas agencias gubernamentales (Ministerio de Agricultura y Cría, MAC Banco Agrícola y Pecuario, BAP, Banco Central de Venezuela, BCV) efectuados a fines de los años 1960 y comienzos de 1970, demostraron que este patrón de intermediación despojaba a los productores campesinos de una porción considerable (el 30\%) del precio paga- 
do por el café en los puertos exportadores o en la industria torrefactora. Aunque el gobierno había creado en 1959 un Fondo Nacional del Café y del Cacao (FNCC) con la misión de facilitar la democratización de la comercialización de estos dos productos, las condiciones permanecian practicamente inalteradas. Medidas como la organización de empresas de productores cafetaleros (Productores Asociados de Café C.A., PACCA), con un aporte económico sústancial por parte del Estado, y de cooperativas de produc. tores Uniones de Usuarios de Créditos) entre aquellos que ahora recibian apoyo crediticio directo del FNCC, no habían logrado desplazar a los intermediarios. ${ }^{7}$ Sólo los productores mayores a nivel nacional, aproximadamente un $8 \%$ del total, vendían en forma directa al FNCC $O$ a las PACCAS en 1972; el resto seguía dependiendo de otros productores, camioneros y/o bodegueros $^{8}$ (véase figura en apéndice). Se necesitaban acciones más drásticas a fin de lograr la modernización e incoporación de los productores campesinos a la economía y sociedad venezolanas, si éstos eran los magros resultados de trece años de una política gubernamental para el café. El retorno de AD al gobierno en las elecciones de 1973, con un andino, Carlos Andrés Pérez, en la presidencia, ofreció la coyuntura para efectuar esas acciones.

7 Momales, "Origine", 1991.

8 BCV, "Cacao", 1978.

\section{Relaciones sociales}

LOCALES EN TORNO DEL MONOPOLIO

ESTATAL DE LA COMERCIALIZACION

CAFETALERA (1974-1991)

En 1974 el gobierno venezolano creó el Fondo Nacional del Café y le otorgó derechos exclusivos sobre la compra y venta de café a nivel nacional e internacional. Además de asegurar precios subsidiados para este producto y asistencia técnica a sus productores, esta organización estatal monopólica incorporó también las otras funciones usualmente controladas por los intermediarios, tales como el otorgamiento de créditos y la venta de insumos agrícolas. Para hacer factible que hasta los más pequeños y aislados productores rurales tuvieran acceso a FONCAFE, éste auspicio la creación de PACCAS a través de todo el país. El gobierno otorgó el mismo derecho a comprar, almacenar y distribuir café, que poseían las PACCAS, a cooperativas independientes de productores, como el Centro Regional de Acopio y Mercadeo (CRAM), fundado en Mérida con apoyo de COPEI en 1969. Tanto las PACCAS como las cooperativas canalizaban café hacia FONCAFE y dinero de éste hacia los productores. Las decisiones con respecto a calidad y precio del café, así como a quién y cuándo venderlo, torrefactores nacionales o mercado internacional, quedaron en manos de la burocracia central del Fondo.?

Ya que las paCcas movilizan el mayor porcentaje de café a nivel nacional, casi el $50 \%$ de ellas se encuentran

\footnotetext{
9 Giacalone, "Rapports", $1991 \mathrm{~b}$.
} 


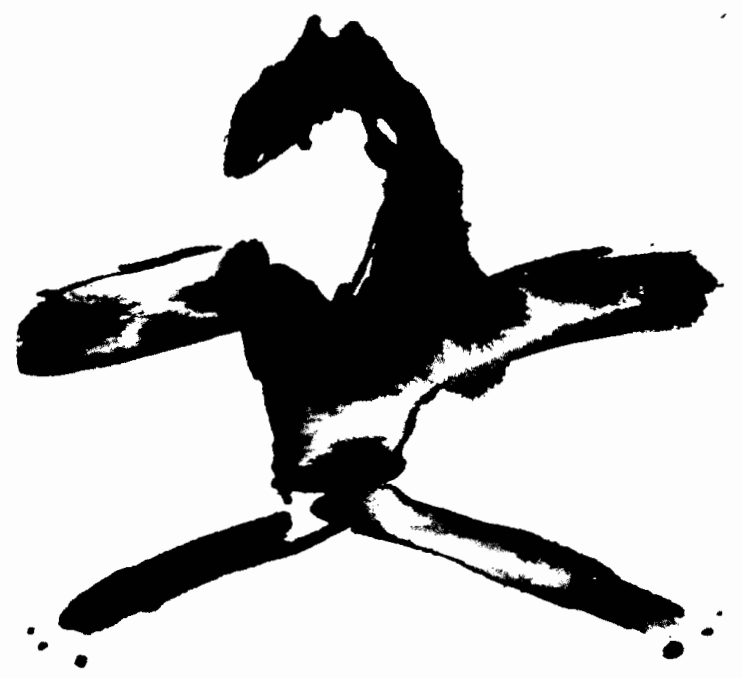

en los Andes (21 de un total de 54) y constituyen el mejor ejemplo de penetración estatal en la región, centraremos nuestra atención en ellas. La máxima autoridad de estas empresas de productores es la asamblea de accionistas que, según sus estatutos, debe reunirse anualmente para elegir su consejo ejecutivo y aprobar, o no, el informe de las actividades efectuadas por el consejo anterior. En este consejo, las dos figuras más importantes son el presidente y el vicepresidente. mientras que el primero es electo por la asamblea, el segundo es nombrado por FONCAFE; el vicepresidente representa el control estatal pues es un empleado pagado por FONCAFE para aprobar o no, las operaciones financieras y memorias anuales de las PAC-
CAS. El fondo también tiene la posiblidad de evaluar periódicamente las actividades administrativas de las empresas y de actuar como comisario en la asamblea anual. Otro elemento clave en la operación de las PACCAS es el gerente, pagado por la empresa misma para encargarse de sus operaciones diarias; la mayor parte de estos gerentes, por lo menos al principio, se reclutaron entre ex empleados de la FNCC. ${ }^{10}$

En los Andes venezolanos el control de las paccas y también de las cooperativas quedó en manos de grupos tradicionales conformados por medianos y grandes productores de café. Un ejemplo claro lo presenta la

${ }^{10}$ Morales, "Origine", 1991. 
constitución de la PACCA de Santa Cruz de Mora, Mérida, en 1975. El Estado, a través de FONCAFE, adquirió entonces 1000 acciones Clase A y la Asociación venezolana de Caficultores (AVC), una asociación nacional controlada por los grandes productores, 622 acciones Clase $B$. El resto de las acciones Clase $B, 378$, fueron compradas por los productores locales. Tres de los cinco productores que compraron el mayor número de estas acciones (120 o sea 32\% del total) formaron el primer consejo ejecutivo. En el caso de CRAM, cinco de los siete miembros que conformaron su primer consejo administrativo provenían de las cuatro Uniones de Usuarios de Créditos (El Portón, San Isidro, La Macana y Chiguará) que habían hecho las mayores contribuciones monetarias para la constitución de la cooperativa. ${ }^{11}$ En otras palabras, en ambos casos los productores locales más poderosos lograron controlar las operaciones del sistema de comercialización cafetalera en la región andina, por medio de su control del consejo directivo en la persona del presidente.

Por su parte, el vicepresidente, proveniente de la burocracia estatal, pudo compartir ese poder debido a su posición central en las operaciones de la empresa. En manos de ellos quedó supervisar operaciones como las realizadas por los gerentes que estaban encargados de comprar café de acuerdo con una tabla de calidad que ellos y sus delegados interpretaban, recomendar o no, la aprobación de créditos a determinados productores, $y$

11 Giacalone, "Development", 1992. vigilar o no, las decisiones que emanaban del consejo ejecutivo. Su experiencia en mercadeo y su conocimiento de cómo opera el aparato burocrático central resultaban necesarias para ese mismo consejo. Pronto vicepresidentes y gerentes se convirtieron muchas veces en productores de café y/o dueños de flotas de camiones que las PACCAS empleaban para el transporte de ese producto a la industria torrefactora o a los puertos. Su conocimiento de la situación cafetalera les permitió adquirir fincas a precios convenientes de aquellos productores que abandonaban el cultivo. Esta asociación con el cultivo o el transporte se tradujo en lazos más cercanos con los productores que controlaban el consejo. Con el tiempo estos burócratas tendieron a no percibir, por ejemplo, que en el caso de la PACCA de Santa Cruz de Mora sólo se realizaron tres asambleas de accionistas en quince años, en lugar de los eventos anuales que mandaban sus estatutos. Así como los consejos y sus presidentes tendieron a perpetuarse en el control de las PACCAS, también los vicepresidentes y gerentes tendieron a mantenerse en sus cargos por diez o doce años. ${ }^{12}$

Un elemento adicional que puede haber contribuido a la constitución de una alianza entre los productores locales más grandes y los burócratas a cargo de supervisar las operaciones de las paccas fue que el sistema de comercialización monopólica del café brindaba a quienes controlaban estas empresas buenas oportunidades de

12 Giacalonc, "Development", 1992. 
beneficiarse en forma económica. En la medida en que las PACCAS y cooperativas constituían puntos de articulación en el funcionamiento del sistema ejercían considerable importancia en las relaciones entre los productores locales y el Estado central. Muchas veces los productores pequeños se quejaron de prácticas tales como la clasificación de su café por parte de las empresas en una categoria inferior a la real, a fin de pagar menos por el mismo, para después venderlo en su verdadera categoría con la ganancia respectiva. Otros se refirieron a pérdidas en el peso del producto. La queja más extendida se relacionaba con la forma de pago del café, a través de un sistema de cuotas a lo largo del periodo de cosecha (octubre de un año a marzo del siguiente), que permitía que quienes controlaban la distribución del dinero a los productores pagaran primero a su familia, asociados y partidarios políticos, antes que al resto. En algunos casos, productores desesperanzados de obtener pronto su pago vendían con un descuento los recibos de las PACCAS a otros productores mayores que los redimían por su valor total; o vendían el café que les quedaba a productores mayores a menores precios (intermediación ilegal) los que luego revendian ese mismo café a las PACCAS como si fuera propio y por la totalidad de su precio..$^{13} \mathrm{El}$ "remanente", la diferencia entre el precio internacional del café y el precio pagado por el Estado venezolano, se empezó a pagar a los productores

13 Giacalone, "Rapports", $1991 \mathrm{~b}$. cafetaleros en 1976, cuando los precios internacionales del café subieron en el mercado internacional; pero el gobierno venezolano se negó a dejar que el precio del producto nacional subiera en la misma proporción a fin de no perjudicar a los consumidores nacionales. Este pago se hacía sobre el monto tutal del café que cada productor vendía cada año y, por tanto, como era imposible prever cuánto café produciría, su pago se hacía después del fin del año cafetalero (octubre-septiembre) y permitía los mismos manejos que el pago de la cosecha.

La principal consecuencia de este comportamiento fue que se constituyeron grupos de poder en torno de las instituciones locales ligadas al Estado con el fin de comercializar café. Los grupos se conformaron con importantes productores tradicionales (algo que puede percibirse al cotejar los apellidos de varios de ellos) y miembros del aparato burocrático de FONCAFE. Su control de las paccas fue posible por la existencia previa de fuertes lazos entre los sectores de poder locales y el campesinado. Además, a partir de 1974, la burocracia venezolana en general se vio afectada por el impacto provocado por el aumento del ingreso petrolero, que hizo crecer en cantidad y complejidad sus operaciones, agregando a la misma gran cantidad de individuos muchas veces no bien preparados para sus cargos. ${ }^{14}$ De esta forma se debilitó considerablemente la capacidad de

${ }^{14}$ Aranda, Economia, 1984; Urbaneja, "Politics", 1991. 
FONCAFE para ejercer una adecuada supervisión de las paccas.

Después de que comenzaron los problemas de la deuda exterior y la caída de los precios internacionales del petróleo, el Estado venezolano se enfrentó cada vez más a la imposibilidad de seguir subsidiando la producción y el consumo de café. El pago tanto de la cosecha como del "remanente" comenzó a experimentar crecientes retrasos que acrecentaron, a su vez, el proceso de enriquecimiento de quienes controlaban las PACCAS y las protestas de los productores contra FONCAFE. ${ }^{15}$ La devaluación del bolívar en 1983 y el fin del sistema de cuotas establecido por la Organización Internacional del Café agregaron dos nuevos elementos: primero, la devaluación de la moneda venezolana volvió a las exportaciones agricolas competitivas en el exterior, $y$, segundo, los precios internacionales de este producto experimentaron un alza considerable aunque de corta duración. Por primera vez desde el establecimiento de FONCAFE, la producción cafetalera parecía capaz de sostenerse y prosperar sin la ayuda del Estado, o al menos así lo pensaron los productores mayores y mejor organizados que comenzaron a presionar para alterar el monopolio en manos del gobierno.

El "Manifiesto de Santa Cruz de Mora", firmado en la ciudad andina sede de una de las PACCAS más importantes de la región, acusó a FONCAFE de ser un obstáculo para la producción cafetalera debido al peso de su burocracia, ineficiencia y corrupción administra-

15 Hellinger, Venezuela, 1992. tiva. La Asociación Venezolana de Cafetaleros (AVC) también se unió a la lucha contra el ente estatal, mediante la presentación de un documento con cuatro demandas básicas: transferir la asistencia técnica de la oficina central de FONCAFE a las PACCAS, otorgar a estas últimas el derecho a comerciar en forma directa, a nivel nacional e internacional, permitirles entrar al rubro de la industria torrefactora y crear un organismo financiero exclusivo para el café. En otras palabras, disminuir el papel de FONCAFE y transferir la mayoría de sus funciones y poderes a las PACCAS.

Finalmente en 1990 el gobierno aceptó algunas de las exigencias de los productores, al entregar a las cuatro PACCAS más poderosas a nivel nacional (dos de ellas ubicadas en los Andes, Rubio y Santa Cruz de Moara) el derecho a comprar y vender café en forma directa. Esta concesión no se otorgó al resto de las empresas por cuanto sólo estas cuatro estaban solventes con el Estado pues habían liquidado todas sus deudas con el mismo. FONCAFE retuvo el derecho a fijar precios mínimos para el café y a comercializar el producto de las otras PACCAS y cooperativas. A comienzos de 1992 la aprobación de la Ley para Promover y Proteger la Libre Competencia significó el fín del monopolio existente. La situación actual es similar a la existente entre 1958 y 1973 cuando el aparato estatal para la comercialización del café, el FNCC, competía en un mercado abierto con intermediarios del sector privado, sólo que ahora en los Andes venezolanos los intermediarios más fuertes son aquellas PACCAs donde se asociaron y prosperaron sectores 
tradicionales locales y burócratas provenientes del aparato estatal.

\section{DISCUSION Y CONCLUSIONES}

Después de quince años de intervención estatal en la comercialización del café en los Andes de Venezuela, resulta evidente: primero, la persistencia de las relaciones de poder local tradicionales entre grandes y pequeños productores de café; segundo, la com. binación exitosa de los productores mayores con los burócratas de las empresas de productores encargadas de comprar, almacenar y vender el café; y tercero, que estas empresas les hayan otorgado un mayor nivel de control sobre los productores pequeños que el que poseían antes, ya que han puesto en sus manos los recursos del Estado.

En forma sucinta las preguntas que nos interesa discutir aquí son dos: ¿Por qué los sectores tradicionales de poder local mantuvieron su control sobre la comercialización del café? y ¿cómo fue que burócratas encargados de implementar una política de desarrollo con objetivos muy distintos llegaron a asociarse con los grupos de poder tradicional?

Con respecto a la persistencia de las relaciones de poder tradicionales, queremos destacar en principio dos interpretaciones que tienen relevancia pero que pueden no ser las únicas válidas - la existencia de pirámides de poder local forjadas a lo largo de generaciones en un área geográfica montañosa y aislada y la presencia de una racionalidad típica de la econo- mía campesina. En el primer caso los grandes productores de café pudieron utilizar esa pirámide de poder en su provecho. Las relaciones piramidales dentro de la región andina se habían constituido desde fines del siglo XIX en torno de la necesidad de asegurar suficiente café para la exportación y/o la industria, pero estaban conformadas también por elementos no necesariamente económicos. De esta forma, lazos familiares, según los cuales, padres y abuelos de los campesinos habían obtr nido su crédito y otras formas de apuy, de una familia o individuo específico más poderoso, un sentimiento de lealtad y aún de orgullo al ser asociado con una familia o persona poderosa, condiciones de extremo aislamiento geográfico donde la dificultad del relieve hacía necesario contar con la ayuda de un grupo mayor y más fuerte que el de la familia campesina, todos estos elementos habrían contribuido al establecimiento y permanencia de lazos no económicos entre los productores mayores y menores a nivel local.

Los créditos, o adelantos de dinero a los productores hasta el momento de la cosecha del café, constituyen un área donde es posible observar que aun después de la intervención estatal las relaciones establecidas tendieron a persistir, al menos para pequeños productores que prefirieron seguir recibiendo sus adelantos de productores locales mayores o bodegueros antes que de las instituciones del Estado. Una ventaja de las relaciones crediticias privadas era que, mientras el Estado sólo adelantaba dinero para la producción del café, los grupos de 


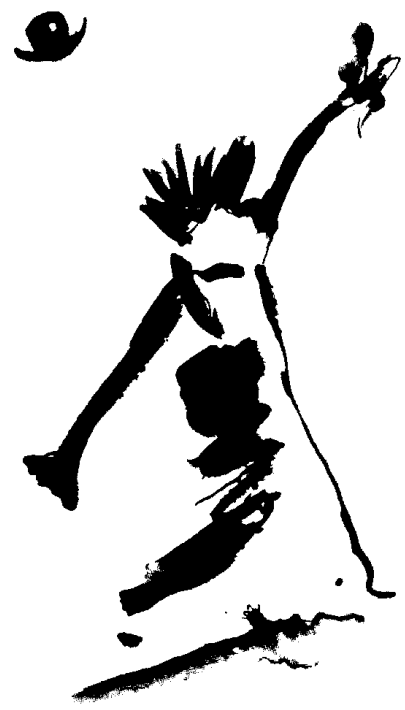

poder locales lo hacian también para otras actividades, tales como en ocasión de la boda de una hija, una enfermedad o muerte en la familia y otros casos similares. En 1988, un observador local con años de residencia en Pueblos del Sur, Mérida, comentaba que los campesinos de esa región preferían endeudarse con gente de la localidad, aunque éstos cobraban intereses mayores, porque con ellos podían hablar si no podían pagar a tiempo. Podían negociar en forma directa con alguien a quien conocian y que, a la vez, los conocía a ellos y a su familia, algo que no podian hacer con el Estado, una autoridad impersonal fuera de su alcance y que podía desposeerlos de su tierra por medio de un documento.
Se ha argumentado que la economía campesina es un segmento de la economía que posee su propia lógica, diferente de la del capitalismo. ${ }^{16} \mathrm{El}$ argumento central es que la unidad campesina combina en sí misma una unidad de producción con una unidad de consumo, en la cual el jefe de familia debe hallar empleo productivo para todos los miembros de su familia; la familia campesina constituye su mano de obra obligada y, a la vez, tiene derecho a compartir los beneficios que se obtienen. Las decisiones campesinas, por tanto, no se basan en expectativas de ganancias en términos capitalistas sino en la necesidad de producir lo suficiente para mante-

${ }^{16}$ Schejtman, "Pcasant", 1980. 
ner y reproducir el núcleo familiar campesino. El objetivo es más genealógico que económico. Una consecuencia directa de esta racionalidad es que los campesinos se resisten a asumir riesgos, a pesar de los beneficios potenciales de los mismos, porque esto puede hacer peligrar la subsistencia de la familia. Esto también hace que las familias campesinas tiendan a apoyarse en "un sistema complejo de intercambios no mercantiles con características de mayor o menor reciprocidad" dentro de su grupo local, lo cual permite la continuación de relaciones tradicionales de poder.

Como resultado de la existencia de relaciones sociales fuertes y de una racionalidad campesina en los Andes venezolanos, puede decirse que fue relativamente fácil para los sectores poderosos de la localidad mantener su papel de intermediarios después de la penetración estatal en la comercialización del café. Para la agricultura campesina, la intermediación con una economía de mercado ha sido siempre un elemento esencial y poderoso, por cuanto el intermediario se encuentra ubicado entre dos modos de producción entre los cuales actúa como puente, pues es capaz de manejar dos tipos de lenguaje, relaciones sociales y racionalidad económica. ${ }^{17}$

En cuanto a por qué los burócratas se asociaron a esos sectores de poder local, posiblemente esa asociación facilitó su tarea en tanto la responsabilidad de estos empleados del Estado consistía en asegurar una provisión regular de café a la industria torrefac-

17 Warman, Venimos, 1980. tora y a la exportación, haciendo llegar a los productores los créditos, asistencia técnica e insumos que el Estado tenía disponibles para ellos. Su posición en el sistema dependía de su habilidad para proveer de café a la economía venezolana y de recursos estatales a los productores. En una región donde carecían de contactos previos y debían enfrentar la desconfianza y los temores de los campesinos, la existencia de sectores tradicionales poderosos, que ya controlaban los elementos económicos (café) y humanos (campesinos) que los burócratas aspiraban a movilizar, probablemente constituía una ventaja. En este sentido Spittler ${ }^{18}$ ha destacado que "no existe nada más dificil que construir una administración que alcance a millones de unidades campesinas autosuficientes". Un estudio del comportamiento de productores cafetaleros de Uganda, África, realizado por Bunker ${ }^{19}$, concluía diciendo que "la única forma en que la burocracia puede funcionar [en este tipo de situación] es a través de intermediarios locales que no se comportan de acuerdo con las reglas abstractas de los burócratas". De esta manera, los grupos locales poderosos, "profundamente enraizados en la organización social autóctona", pueden mediar entre la burocracia y los campesinos que el Estado necesita movilizar en un momento dado.

En los Andes venezolanos, esta asociación entre grupos de poder local tradicionales y burócratas estatales, se

18 Spittler, "Administration", 1983.

19 Bunker, "Pcasants", 1987. 
tradujo en beneficios mutuos. No sólo permitió que estos últimos adquirieran riqueza y poder, sino que también aseguró que los productores cafetaleros mayores y sus asociados obtuvieran acceso preferencial a los recursos del Estado. Su posición en los puntos de articulación del sistema garantizó que parte de esos recursos quedaran, tanto en mano de burócratas como de cafetaleros poderosos, sin alcanzar a cumplir el objetivo original que había determinado la creación del sistema de comercialización estatal del café.

Antes de concluir, queremos intentar algunas observaciones de carácter comparativo que pudieran eventualmente convertirse en hipótesis para trabajos ulteriores. Con respecto a la penetración estatal en la producción cafetalera de Colombia, Palacios ${ }^{20}$ concluye que esta intervención no tuvo por fin transformar las estructuras existentes sino paliar los efectos más traumáticos de los ciclos del café, en el mercado internacional, sobre el ingreso de los productores más pequeños. El sector privado cafetalero, o sea los grandes productores, es el que dirige la política del café y esta política del Estado resulta un instrumento para proteger al sector privado. Los pequeño productores campesinos, aun siendo la mayoría de los productores cafetaleros, permanecen, en cierta medida, al margen del mercado y sus ciclos de alzas y bajas, por cuanto la mayoría de ellos cultiva sus propios alimentos. Palacios destaca a su vez la fuerza que tiené la Federación Nacional de Cafeteros de Colombia (FNCC)

${ }^{20}$ Palacios, Coffee, 1976. en la dirección de la política del café a nivel nacional y cómo esa asociación se encuentra dominada por sectores tradicionales poderosos de la producción (hacendados) y exportadores. Este grupo no actúa como un grupo de interés compitiendo con otros dentro de una sociedad pluralista; se apropia en cambio funciones que, al menos en teoría, debieran corresponder al Estado y, en la década de 1940, inclusive aumentó su patrimonio al mezclarlo con el del estatal Fondo Nacional del Café. La política desarrollista, iniciada en los año 1960, trataba de mejorar la productividad y eficiencia en el café, con lo cual, las unidades campesinas de producción cafetalera han tendido a desaparecer o a ser relegadas de la atención estatal.

Anthony Winson, en su libro Coffee and democracy in modern Costa Rica ${ }^{21}$ por su parte señala que, en ese país, se ha desarrollado un sector moderno de productores de café que ha conseguido aumentar su influencia económica, social y política mediante su monopolio de las operaciones de procesamiento y exportación y del suministro de créditos a los pequeños productores. La productividad de este sector cafetalero creció, gracias a un paquete tecnológico promovido por el Estado, mediante asistencia técnica y créditos, el cual incluía nuevas variedades de café y nuevas técnicas de manejo (más pesticidas y menos mano de obra), con lo cual, la mano de obra campesina con pequeñas parcelas de café dentro de las haciendas se vio desplazada. Aquí también el pro-

21 Winson, Coffee, 1989. 
ceso de modernización cafetalera ha servido a los intereses de los grandes productores $y$ ha contribuido a desplazar a los productores campesinos. Si bien esta política logró modernizar y hacer más eficiente la producción de café a todos los niveles, en sentido económico los productores que más se beneficiaron fueron los grandes. Él concluye que,

después de una considerable reestructuración de productores-procesadores en los 50 y 60 , el núcleo económico de los productores capitalistas de calé emergió básicamente más fuerte como clase, en comparación con su posición al comienzo de este periodo.

Nuestro conocimiento lamentablemente incompleto acerca de la realidad cafetalera, tanto de Colombia como de Costa Rica, no nos permite evaluar la exactitud de las conclusiones anteriores, pero ellas nos sugieren la necesidad de rever la penetración del Estado venezolano en la producción y comercialización del café entre 1974 y 1992 desde nuevas perspectivas. Para ello es necesario realizar un análisis más amplio, a nivel nacional, de la interrelación AVC-FONCAFE-PACCAS, así como una reevaluación, quizá a nivel regional, de cómo ha variado la situación de los productores campesinos de café durante el periodo de monopolio estatal cafetalero.

\section{NoTAS}

1. Este trabajo es el resultado de una investigación financiada por el Conse- jo de Desarrollo Científico y Humanistico (CDCH) de la Universidad de Los Andes, Mérida, Venezuela. La mayor parte de nuestros datos se obtuvieron mediante trabajo de campo en la zona de los Pueblos del Sur de Mérida, entrevistas en las oficinas centrales de FONCAFE y en PACCAS y cooperativas locales, análisis de documentos oficiales $e$ información periodística entre 1988 y fines de 1991. En Pueblos del Sur se observó el predominio de productores cafetaleros con menos de nueve hectáreas en producción que además se caracterizan por compartir características tales como utilización exclusiva de mano de obra familiar, técnicas y variedades tradicionales en el cultivo, poco uso de fertilizantes y pesticidas. Así como otros elementos tradicionales que nos permiten clasificarlos en general como productores campesinos.

2. En los Andes venezolanos, las oficinas técnicas de FONCAFl promovieron un programa tecnológico similar entre 1975 y mediados de la década de 1980.

BIBLIOGRAFIA

- Aranda, Sergio, La economía venezolana, Caracas, 1984 .

-Atarolf, M. y R. Giacalone, Aplicacton de prueba piloto para un estudio integrado de los agroecosistemas cafetaleros de los Pueblos del Sur de Mérida, Mérida, 1988.

Banco Central de Venezuela (sncv, $\mathrm{Ca}$ cao-Café-Caña de Azúcar-Tabaco. Estudio integral del sector, Caracas, 1978. 
-Banco Agropecuario (BAP), El BAP y el café, Caracas, 1968.

-Bunker, S. G., Peasants against the State, Urbana, Ill. 1987.

Correo de los Andes, Mérida.

-CRAM. Acta Constitutiva, Reglamento

y Estatutos, San Cristóbal, Táchira, 1979.

-FONCAFE, 1985-1986-1987-1988. Me-

moria y Cuenta, Caracas.

-Frontera, Mérida.

-Giacalone, R., "Relaciones clientelistas en la comercialización del café en Venezuela", Washington, D.C.: Conferencia Internacional de LASA, 1991 .

-, "Rapports anciens et nouveaux autour de la commercialisation du Café dans les Andes vénézuéliennes", GEODOC, núm. 36, Toulouse, Francia, 1991b.

, "Development policy in the

venczuelan Andes: The case of coffee commercialization", Journal fur Entwicklungspolitik, vilı, núm. 4, Viena, Austria, 1992.

-Hellinger, Daniel C., Venezuela: Tarnished democracy, Westview Press, Boulder, Colorado, 1992.

-Haynes, L., Coffee growing in the venezuelan Andes, Mérida, s.a.

-López, R. A. y D. Dorsainvil, "An analysis of pricing in the haitian coffee market", The Journal of Developing Areas, octubre, 1990.

-Lord, Peter P., The peasantry and emerging political factor in Mexico, Bolivia $y$ Venezuela, The Land Tewre Center núm. 35, Madison, Wisconsin, 1967.

-Ministerio de Agricultura y Cría (MAC), Estudio integral de la caficultura en Venezuela, Caracas, 1974.

-Ministerio de Agricultura y Cría (MAC), El café en Venezuela, Caracas, 1967.

-MARNR, Los procesos agroeconómicos: Café, Caracas, 1982.

-Morales, A. F., "Origine historique et fonctionnement des paccas dans les Pueblos del Sur de L'État de Mérida", GEODOC, núm. 36, Toulouse, Francia, 1991.
-El Nacional, Caracas.

-PACCa Santa Cruz de Mora, Estatutos. Documento Constitutivo, Mérida, 1976.

-PACCA Santa Cruz de Mora, Informe de la Junta Administradora 1/04/86 a 31/03/90, Mérida, 1990.

-Palacios, M., Coffee in Colombia 1850-1970, Cambridge, Mass., 1980.

-Panorama, Maracaibo.

-Pouyllau, M., "Base territoriale et socio-culturelle d'un pouvoir national et regional: Le cas du Tachira, 1870-1982" en J. Revel-Mouroz (comp.), Venezuela: centralisme, regionalism e pouvoir local, Paris, Francia, 1988.

-Powell, John D., Polttical mobilization of the venezuelan peasant, Harvard University Press, Cambridge, 1971.

-Roseberry, William, Coffee and capitalism in the venezuelan Andes, University of Texas Press, Austin, 1983.

-Samudio, E. y G. Monsalve, "La production cafetière dans l'ítat de Mérida en 1940", GEODOC, núm. 36, Toulouse, Francia, 1991.

-Schejtman, A., "The Peasant Economy: Internal Logic, Articulation and Persistence", CEPAL Review, agosto 1980.

-Spittler, G., "Administration in a Peasant State", Sociologia Ruralis, 1983.

-Tulet, J. C., "Le role essential du café dans les Andes vénézuéliennes", GEO $D O C$, núm. 36, Toulouse, Francia, 1991.

-UNET, FONCAFE, Diagnóstico integral de la caficultura tachirense, San Cristóbal, Táchira, 1987.

El Universal, Caracas.

-Urbaneja, D. B., "Politics and society in Venczucla", en C. Clarke (comp.), Soctety and Polttics in the Caribbean, Londres, 1991.

-El Vigilante, Mérida.

-Warman, A., Y venimos a contradecir..., México, 1976.

-Winson, A., Coffee and democracy in modern Costa Rica, Nueva York, 1989. 


\section{SECUENCIE}

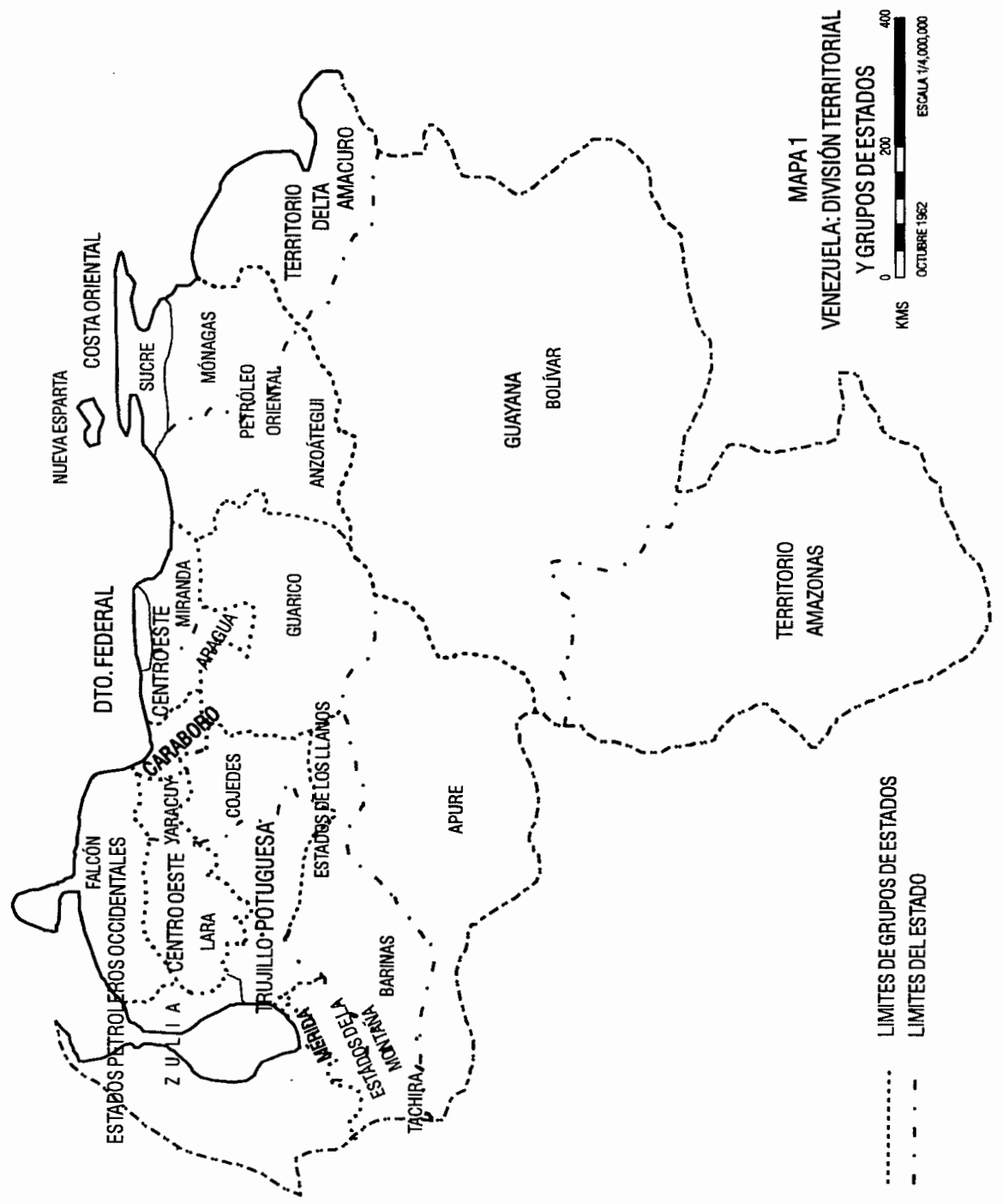


Gráfica: Canales de mercadeo de café en 1973

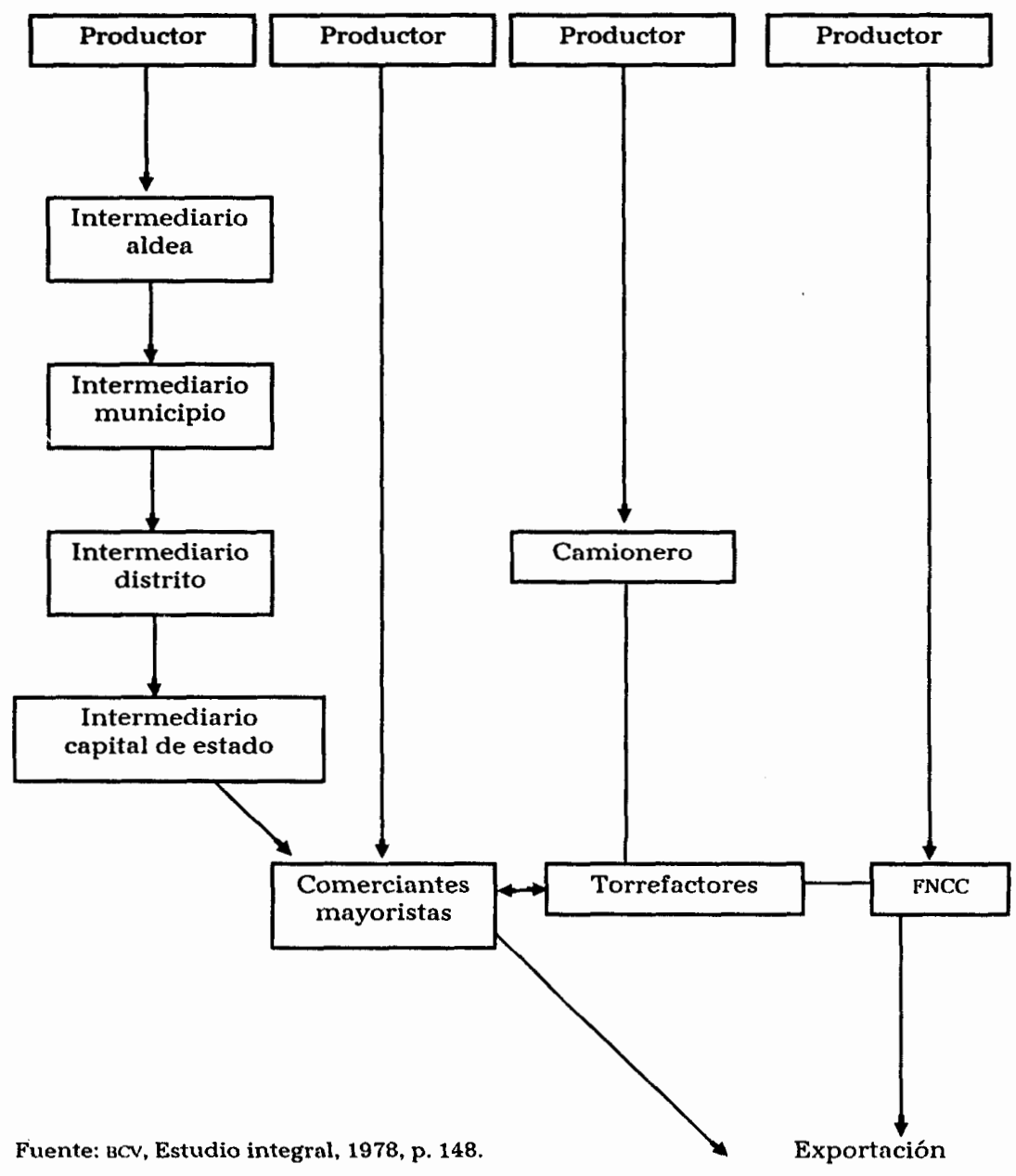

